\title{
Inferior alveolar nerve block: is articaine better than lidocaine?
}

\author{
Hannah Hook'
}

\section{Key points}

Compares the composition of lidocaine and articaine.

Discusses and compares research regarding risk of paraesthesia.
Explores success, onset and duration of anaesthesia.

Abstract

This opinion article seeks to analyse current literature surrounding the question: is articaine better than lidocaine for inferior alveolar nerve blocks? It does so with regards to efficacy and risk of paraesthesia associated with administration.

\section{Introduction}

Pain is an undeniably common phenomenon and also a likely perception of what a trip to the dentist may entail. Even the least invasive dental procedure may evoke the notion of pain, exacerbating a patient's anxiety and phobia, and ultimately considerably impacting the avoidance of dental care. Eventually, these barriers can result in poor oral health and increased treatment needs.

Effective pain management is not only a necessity for the successful provision of many dental treatments; it is the duty of the dentist and also an expectation of the patient that their pain and anxiety will be managed appropriately. Therefore, the recognition of the significance of providing patients undergoing invasive dental procedures with profound anaesthesia is imperative. ${ }^{1}$

Inferior alveolar nerve blocks (IANBs) are often the first choice for gaining pulpal anaesthesia in mandibular teeth, especially mandibular molars; however, efficacy has been shown to be somewhat diverse. One author reported inadequate anaesthesia was experienced in $15-20 \%$ of cases ${ }^{2}$ and another

'Browns Dental Practice, Cedar Rise, Fore Street, Ivybridge, PL21 9AE, UK.

Correspondence to: Hannah Hook

Email address: hannah_hook@outlook.com

Refereed Paper

Accepted 1 December 2020

https://doi.org/10.1038/s41415-021-2941-z suggested that $45 \%$ of IANBs fail. ${ }^{3}$ Conversely, one clinical audit deemed $92 \%$ of 580 IANBs to be successful in gaining profound anaesthesia. ${ }^{4}$

The varied success rates of IANBs prompt ongoing research into which local anaesthetic solution is the most effective in providing safe and successful anaesthesia when administered via IANBs. With articaine and lidocaine being the most commonly used local anaesthetics in dentistry, ${ }^{5,6}$ the overarching question remains: is articaine better than lidocaine and can it be used for an IANB?

\section{Local anaesthetic popularity}

Lidocaine hydrochloride (HCL) has upheld a good reputation, over time becoming the gold standard for dental professionals in the United Kingdom (UK). Originally synthesised in 1943, lidocaine was the first amide anaesthetic. ${ }^{7}$ It has been used in dentistry for more than 70 years and, while it remains the most widely available and popular anaesthetic of choice in the UK, ${ }^{5}$ its sales have decreased dramatically since $1998 .{ }^{8}$ This could be partly attributed to the increased use of a much newer anaesthetic, ${ }^{9}$ articaine HCL. Originally synthesised in 1969, ${ }^{7}$ articaine was initially introduced into practice in Germany in 1976, Canada in 1984 and the UK in $1998 .{ }^{10}$ Articaine subsequently hit the market in the rest of Europe and the United States in 2000 and Australia in 2005.,10

Since the introduction of articaine to the market, the gold standard of local anaesthetic has varied worldwide. Articaine is predominantly used as a first-line anaesthetic in various European countries (the Netherlands, France, Germany and Italy) along with Canada. ${ }^{6,11}$ One study reported that in Germany, articaine accounts for $90 \%$ of local anaesthetic used by dentists. ${ }^{12,13}$ While the UK still favours a conservative approach to the use of articaine in dentistry, sales of the local anaesthetic continued to rise following its introduction, almost reaching the sale of ten million cartridges in $2008,{ }^{8}$ with one study reporting that newly qualified dentists tend to use articaine more frequently. The most widely used formulation of articaine in dentistry is currently $4 \%$ with adrenaline $1: 100,000$ or $1: 200,000(5 \mu \mathrm{g} /$ $\mathrm{mL}) ;{ }^{10,14}$ however, studies have shown no clinical advantage of a $4 \%$ solution over a $2 \% .^{15,16}$

\section{Physical and chemical properties}

In contrast to other local anaesthetics, articaine contains a thiophene ring rather than a benzene ring (Table 1), allowing for an enhanced lipid solubility and thus increased diffusion of the anaesthetic across the nerve membrane, and therefore an amplified drug potency four times greater than that of lidocaine. ${ }^{8}$ Additionally, articaine is the only amide anaesthetic to contain an ester group, enabling rapid hydrolysis by serum esterases immediately following injection. ${ }^{17}$ It is postulated that the beneficial relationship between persistence of local anaesthetic and low systemic toxicity may be attributed to a local saturation of serum esterases, resulting in slower and prolonged metabolism. ${ }^{18}$ 
Articaine with a protein binding of 95 is greater than that of lidocaine at 65 ; this allows articaine to have a superior impact on duration of anaesthesia. ${ }^{19}$ It has been noted that the duration of anaesthesia of articaine with adrenaline is up to 15 minutes longer for pulpal anaesthesia and up to 60 minutes longer for soft tissue anaesthesia in comparison to lidocaine with adrenaline ${ }^{19}$ (Table 1), providing a longer working time for the clinician and more comfort for the patient. However, both articaine and lidocaine have a similarly low $\mathrm{pKa}$, which acts to enhance their diffusion, providing a rapid onset of anaesthesia. ${ }^{8,19}$ Despite its described positive characteristics, a significant concern regarding the use of articaine in dentistry surrounds the reports of paraesthesia, especially when being used for IANBs.

\section{Systemic effects}

Adverse effects are not restricted to one local anaesthetic, with all possessing the potential to be unsafe. Side effects can include dizziness, convulsions, tremors, seizures, disorientation, hypotension, and respiratory and cardiac overdose is reduced in articaine, due to its quick metabolism into an inactive metabolite, proving it to be one of the safer local anaesthetics in this respect. ${ }^{17}$ The formulation of articaine enables not only increased lipid solubility but also the provision of a higher number of molecules in comparison to an equal volume of $2 \%$ lidocaine. Hydrolysis depression. ${ }^{14}$ The risk of systemic toxicity and

of articaine by serum esterases results in an elimination half-life of 20 to 40 minutes, significantly less than that of lidocaine which requires $>90$ minutes for hepatic clearance. ${ }^{20}$ This attractive property of articaine allows for a $4 \%$ concentration; lidocaine administered in a $4 \%$ concentration would pose an unacceptable risk for systemic toxicity. Therefore, where lengthy appointments are required for dental treatment, articaine presents a lower risk for systemic toxicity. However, it is worth bearing in mind that per volume administered, $4 \%$ articaine contains twice the dose of $2 \%$ lidocaine, yet their recommended doses are identical. $^{20}$

\section{Anaesthetic efficacy}

A 2018 Cochrane review explored the success of anaesthesia, the speed of onset and the duration of anaesthesia among different local anaesthetic formulations for dental anaesthesia, including $4 \%$ articaine and $2 \%$ lidocaine. ${ }^{21}$ The success of anaesthesia, defined as 'the absence of pain', was greater in the $4 \%$ articaine group compared to that of $2 \%$ lidocaine when treating posterior teeth with irreversible pulpitis. ${ }^{21}$ A meta-analysis and systematic review further supported the use of $4 \%$ articaine over $2 \%$ lidocaine, suggesting that articaine provides a higher rate of anaesthetic success and also has a safety comparable to that of lidocaine when used for IANB. ${ }^{22}$ Tortamano et al. undertook a clinical trial that revealed, when used for IANB, $4 \%$ articaine exhibited a quicker onset

Table 1 Table displaying physical and chemical properties of lidocaine and articaine, adapted with permission from G. Bartlett and J. Mansoor, 'Articaine buccal infiltration vs lidocaine inferior dental block - a review of the literature', British Dental Journal, 2016, Springer Nature ${ }^{8}$

\begin{tabular}{l|l|l}
$\begin{array}{l}\text { Physical/chemical } \\
\text { property }\end{array}$ & Lidocaine \\
\hline Chemical structure & 234 & 248 \\
\hline Molecular weight & Benzene ring & 7.8 \\
\hline pKa & 7.9 & 17 \\
\hline Lipid solubility & 4 & 95 \\
\hline Protein binding (\%) & 65 & $\begin{array}{l}\text { Pulpal }=60-75 \text { minutes } \\
\text { Soft tissue }=180-360\end{array}$ \\
\hline $\begin{array}{l}\text { Duration of } \\
\text { anaesthesia (minutes) }\end{array}$ & $\begin{array}{l}\text { Pulpal }=60 \text { minutes } \\
\text { Soft tissue }=180-300\end{array}$ \\
\hline
\end{tabular}

and longer duration of pulpal anaesthesia when compared to $2 \%$ lidocaine, with mean onset of pulpal anaesthesia in mandibular molars more than one minute quicker $(\mathrm{p}=0.037)$ and duration of pulpal anaesthesia 62 minutes longer under articaine $(\mathrm{p} \leq 0.05) .{ }^{23}$ Additionally, the results of a meta-analysis carried out by Brandt et al. demonstrated articaine to be 1.6-3.5 times more potent than lidocaine. ${ }^{1}$ This report also described articaine to be more likely to produce successful anaesthesia than lidocaine, indicating that it is an advantageous choice of anaesthetic. This was strongly supported with infiltration anaesthesia; however, the evidence was weak when comparing anaesthetics for mandibular block anaesthesia. Poorni et al. ${ }^{24}$ also found no difference for overall success between articaine and lidocaine after IANB in mandibular molars with irreversible pulpitis.

\section{Sites of paraesthesia}

A study by Garisto et al. ${ }^{25}$ explored reports of paraesthesia after dental local anaesthetic, discovering that out of 219 cases of paraesthesia, 207 involved an IANB. While it is the inferior alveolar nerve we aim to anaesthetise, the lingual nerve seems to have a predilection to develop paraesthesia after IANB, both temporarily and in the long term. When looking at anatomical structures affected by paraesthesia after dental local anaesthetic, the lingual nerve was affected in $78-89 \%$ of cases, the mental nerve in $7 \%$ of cases and $4 \%$ of cases involved both nerves. ${ }^{26}$ Research by Pogrel et al. ${ }^{27}$ speculated that the lingual nerve was most likely to be affected due to it sometimes being unifascicular, in comparison to the inferior alveolar nerve which was found to always be multifascicular. This currently seems to remain the most probable reason for the tendency of the lingual nerve to develop paraesthesia. ${ }^{27}$ Many cases of paraesthesia may be temporary and are suggested to resolve within eight weeks post-injection; however, some injuries may be permanent, allowing partial or no recovery. ${ }^{28}$

\section{Causes of paraesthesia}

The exact cause of paraesthesia after injection is not certain, but it is speculated to be attributed to one or a combination of various factors: direct contact of the needle with the nerve resulting in trauma, hydrostatic pressure caused by the injection, haemorrhage into the nerve following injection or neurotoxicity of the local anaesthetic leading to degeneration of 
axon or myelin cellular structures. ${ }^{25}$ However, controversy still surrounds the hypothesis that local anaesthetics may be neurotoxic. ${ }^{26,29}$

A 1995 retrospective examination of non-surgical paraesthesia cases by Haas and Lennon ${ }^{30}$ raised the issue of potential neurotoxicity of local anaesthetics after their findings in regard to $4 \%$ articaine and $4 \%$ prilocaine, which they found to be the two anaesthetics most commonly implicated with paraesthesia. This is consistent with findings from a study by Gaffen and Haas, ${ }^{31}$ in which $4 \%$ articaine and $4 \%$ prilocaine were most frequently associated with paraesthesia than any other dental local anaesthetics. Further to this, a study in Denmark by Legarth found that $4 \%$ articaine was involved in $88 \%$ of reports of neuropathy after local anaesthetic injection. ${ }^{32}$ Multiple studies have demonstrated significant neurotoxicity for $4 \%$ articaine solutions when compared with lower concentrations, representing a dose and concentration relationship for both lidocaine and articaine. ${ }^{32,33}$ However, as apparent from above, $2 \%$ lidocaine is rarely implicated in causing adverse effects such as paraesthesia after its use for IANB, highlighted by its infrequency in the data from the studies. Despite these various studies attributing the articaine-related injuries to its high concentrations, Hillerup et al. suggest this may not exclusively be the cause. Its increased lipid solubility and protein binding may also contribute to the neurotoxicity. ${ }^{34}$

However, recent evidence also exists contradicting these claims. A 2016 study by Su et al. found $4 \%$ articaine to have a higher success rate of anaesthesia, a shorter onset time and a lower percentage of adverse events including paraesthesia. ${ }^{35}$ Furthermore, in the 2018 Cochrane review, St George et al. concluded that adverse events for both $4 \%$ articaine and $2 \%$ lidocaine were rare. ${ }^{21}$ The main unwanted adverse effect was pain on injection, in which there was no difference between the two anaesthetic groups, and postinjection pain following the disappearance of the anaesthetic, which was slightly less for $2 \%$ lidocaine; however, the difference was minor. ${ }^{21}$

\section{Sales distribution and paraesthesia}

UK

In the UK, the Yellow Card Scheme allows for recording of adverse incidents. In the period of 1998 to 2008, reports of paraesthesia following administration of local anaesthetic included 44 cases of sensory disturbances. Of these cases,
$77 \%$ were associated with administration of articaine and $16 \%$ with lidocaine. ${ }^{9}$ Sales distribution of anaesthetics at this time was approximately $70 \%$ for lidocaine and $13 \%$ for articaine. $^{9}$

\section{Europe}

Hillerup and Jensen investigated patients with lingual nerve damage following IANB during 1997 to $2004 .{ }^{26}$ The study found that despite articaine's recent introduction into the market in $2000,87 \%$ of cases of paraesthesia were attributed to the local anaesthetic, while it had a 42\% market share. During 2001 and 2002, a twentyfold increase in incidence of nerve damage following articaine IANB in comparison was reported. ${ }^{25}$ A later study examining the period of 2001 to 2007 conducted by the same authors found 181 reports of paraesthesia following the use of local anaesthetic..$^{29}$ Of these reports, articaine was the anaesthetic administered in $78 \%$ of the cases, while having a $41 \%$ share in the market. ${ }^{29}$

These findings are similar to the findings from a questionnaire distributed by the Dutch Dental Association in 2003 investigating sensibility disorders related to local anaesthetic. The survey found that articaine had been administered in $89 \%$ of the cases of paraesthesia following IANB. ${ }^{36,37}$

\section{Canada}

Haas and Lennon ${ }^{30}$ carried out a 21 -year retrospective study investigating reports of paraesthesia following local anaesthetic administration. The study found 143 cases of paraesthesia, 14 of which were reported in 1993. Articaine was the anaesthetic used in $71 \%$ of these cases and had a market share of $38 \%$ at the time. ${ }^{30}$ Incidence of dental local anaesthetic paraesthesia started to increase in 1985, shortly after articaine's introduction into the Canadian market, following a pattern similar to that reported by Hillerup and Jensen. ${ }^{26}$

\section{United States}

Prior to the release of articaine into the United States, a similar study by Pogrel et al. highlighted lidocaine to be involved with $67 \%$ of cases of lingual nerve paraesthesia following IANB. ${ }^{38}$ This was later contradicted in a study examining the period from 2003 to 2005 investigating 57 patients who were referred to the oral and maxillofacial department at the University of California due to nerve injuries acquired from IANBs. ${ }^{39}$
Of these cases of paraesthesia, lidocaine was responsible for $35 \%$ and articaine for $30 \% .{ }^{39}$ Pogrel continued this research during the period of 2006 to 2011, finding a further 41 cases, of which lidocaine was responsible for $25 \%$ and articaine $33 \%{ }^{40}$

Both of these studies reflected a similar representation of articaine usage and market share, with an estimated distribution of $30 \%$ in 2003 to $2005^{39}$ and $38 \%$ in 2006 to $2011 .^{40}$

Garisto et al. ${ }^{25}$ documented articaine to have a frequency of paraesthesia 3.6 times greater than expected ( $\mathrm{p}<0.0001)$ when compared to the market distribution. Conversely, lidocaine had a much lower observed frequency of paraesthesia compared to what was expected. ${ }^{25}$

\section{Conclusion}

After reviewing the current literature, it is apparent that there is no unanimous decision when looking at whether articaine is superior to lidocaine for IANB. Examination of the literature demonstrates an over-representation of cases of paraesthesia as a result of articaine IANB in relation to its market share. However, uncertainty still surrounds the probability of articaine to cause paraesthesia, with the multiple studies available offering conflicting results and opinions on this matter.

While various studies agree that articaine outperforms lidocaine, providing a faster onset and prolonged pulpal anaesthesia, this was more commonly found when the local anaesthetic was administered via infiltration rather than IANB. When weighing up the information, it seems the possible benefits of an increased onset and duration of pulpal anaesthesia do not outweigh the potential risk of permanent paraesthesia after an articaine IANB. Therefore, it may be reasonable to conclude that, while the evidence surrounding the question is articaine better than lidocaine?' is insufficient, lidocaine anaesthetic still provides (and has for many years) a safe and effective measure of providing anaesthesia via IANB, ultimately remaining the gold standard in the UK. It is clear that the use of $4 \%$ articaine in the UK is becoming increasingly popular, especially with newer graduates, and if current trends continue, it may become the new gold standard in the future. While the amount of research available is continually developing, further studies, especially randomised controlled trials, are required to increase the strength of the evidence and help clinicians make an informed decision as to which local anaesthetic to choose when carrying out a dental block. 


\section{Conflict of interest}

The author declares no conflict of interest.

\section{References}

1. Brandt R G, Anderson P F, McDonald N J et al. The pulpal anaesthetic efficacy of articaine versus lidocaine in dentistry a meta-analysis. J Am Dent Assoc 2011; 142: 493-504.

2. Malamed S F. Handbook of local anaesthesia. 5th ed. St Louis: Mosby, 2004

3. Potočnik I, Bajrović F. Failure of inferior alveolar nerve block in endodontics. Endod Dent Traumatol 1999; 15: 247-251.

4. Keetley A, Moles D R. A clinical audit into the success rate of inferior alveolar nerve block analgesia in general dental practice. Prim Dent Care 2001; 8: 139-142.

5. Corbett I P, Ramacciato J C, Groppo F C et al. A survey of local anaesthetic use among general dental practitioners in the UK attending postgraduate courses on pain control. Br Dent J 2005; 199: 784-787.

6. Johansen $\emptyset$. Comparison of articaine and lidocaine used as dental local anaesthetics. Norway: University of Oslo, 2004. Thesis.

7. Rahn R, Ball B. Local anaesthesia in dentistry-articaine and edrenaline for dental anaesthesia. 1st ed. Seefeld: 3M, 2001

8. Bartlett G, Mansoor J. Articaine buccal infiltration vs lidocaine inferior dental block - A review of the literature. Br Dent J 2016; 220: 117-120.

9. Zahedi S. Retrospective review of dental local anaesthetic induced paraesthesia in the United Kingdom. Toronto: University of Toronto, 2012. MSc Thesis.

10. Snoeck M. Articaine: A review of its use for localand regional anaesthesia. Local Reg Anesth 2013; 5: 23-33.

11. Ezzeldin M, Hanks G, Collard M. United Kingdom paediatric dentistry specialist views on the administration of articaine in children. J Dent Anesth Pain Med 2020; 20: 303

12. Malamed SF, Gagnon S, Leblanc D. Articaine hydrochloride: A study of the safety of a new amide local anaesthetic. J Am Dent Assoc 2001; 132: 177-185.

13. Malamed S, Gagnon S, Leblanc D. A comparison between articaine $\mathrm{HCl}$ and lidocaine $\mathrm{HCl}$ in paediatric dental patients. Paediatr Dent 2000; 22: 307-311.
14. Yapp K E, Hopcraft M S, Parashos P. Articaine: A review of the literature. Br Dent J 2011; 210: 323-329.

15. Hintze A, Paessler L. Comparative investigations on the efficacy of articaine $4 \%$ (edrenaline 1:200,000) and articaine $2 \%$ (edrenaline $1: 200,000$ ) in local infiltration anaesthesia in dentistry - A randomised double-blind study. Clin Oral Investig 2006; 10: 145-150.

16. Fritzsche C, Pässler L. Ultracain D-S und ultracain $2 \%$-suprarenin-vergleichende untersuchungen zur lokalanästhesie in der zahnärztlichen chirurgie. Quintessenz 2000; 51: 507-514.

17. Oertel R, Rahn R, Kirch W. Clinical pharmacokinetics of articaine. Clin Pharmacokinet 1997; 33: 417-425.

18. Oertel $R$, Berndt A, Kirsch W. Saturable in vitro metabolism of artiaine by serum esterases: Does it contribute to the persistence of the local anaesthetic effect? Reg Anesth 1996; 21: 576-581.

19. British Dental Association. Lignocaine vs Articaine in Dentistry - BDA evidence summary: 2016. 2016

20. Becker D E, Reed K L. Local anaesthetics: review of pharmacological considerations. Anesth Prog 2012; 59: 90-101, quiz 102-103.

21. St George G, Morgan A, Meechan J et al. Injectable local anaesthetic agents for dental anaesthesia. Cochrane Database Syst Rev 2018; DOI: 10.1002/14651858. CD006487.pub2.

22. Katyal V. The efficacy and safety of articaine versus lignocaine in dental treatments: A meta-analysis. J Dent 2010; 38: 307-317.

23. Tortamano I P, Siviero M, Lee S et al. Onset and duration period of pulpal anaesthesia of articaine and lidocaine in inferior alveolar nerve block. Braz Dent J 2013; 24: 371-374.

24. Poorni S, Veniashok B, Senthilkumar A D et al. Anaesthetic efficacy of four percent articaine for pulpal anaesthesia by using inferior alveolar nerve block and buccal infiltration techniques in patients with irreversible pulpitis: A prospective randomized doubleblind clinical trial. J Endod 2011; 37: 1603-1607.

25. Garisto G A, Gaffen A S, Lawrence H P, Tenenbaum H C Haas D A. Occurrence of Paresthesia After Dental Loca Anaesthetic Administration in the United States. J Am Dent Assoc 2010; 141: 836-844.

26. Hillerup $S$, Jensen R. Nerve injury caused by mandibular block analgesia. Int J Oral Maxillofac Surg 2006; 35: 437-443.
27. Pogrel M A, Schmidt B L, Sambajon V et al. Lingual nerve damage due to inferior alveolar nerve blocks: A possible explanation. J Am Dent Assoc 2003; 134: 195-199.

28. Haas D A. An update on local anaesthetics in dentistry. J Can Dent Assoc 2002; 68: 546-551.

29. Hillerup S, Jensen R H, Ersbøll B K. Trigeminal nerve injury associated with injection of local anaesthetics Needle lesion or neurotoxicity? J Am Dent Assoc 2011; 142: 531-539.

30. Haas D A, Lennon D. A 21 year retrospective study of reports of paresthesia following local anaesthetic administration. J Can Dent Assoc 1995; 61: 319-320, 323-326, 329-330

31. Gaffen A, Haas D. Retrospective review of voluntary reports of nonsurgical paresthesia in dentistry PubMed. J Can Dent Assoc 2009; 75: 579.

32. Legarth J. Skader pa nervus lingualis opstaet forbindelse med mandibularanalgesi - anmeldt til Dansk Tandlaegeforenings Patientskadeforsikring 2002-2004. Tandlaegebladet 2005; 109: 786-788.

33. Kroin J S, Penn R D, Levy F E et al. Effect of repetitive lidocaine infusion on peripheral nerve. Exp Neurol 1986; 94: $166-173$

34. Hillerup S, Bakke M, Larsen J 0 et al. Concentrationdependent neurotoxicity of articaine: An electrophysiological and stereological study of the rat sciatic nerve. Anesth Analg 2011; 112: 1330-1338.

35. Su N, Li C, Wang H et al. Efficacy and safety of articaine versus lidocaine for irreversible pulpitis treatment: $\mathrm{A}$ systematic review and meta-analysis of randomised controlled trials. Aust Endod J 2016; 42: 4-15.

36. NMT. Omnibus-enquête najaar 2003: Sensibiliteitsstoornissen bij patiënten na lokale anaesthesie. 2004

37. Hopman A J G, Baart J A, Brand H S. Articaine and neurotoxicity - A review. Br Dent J 2017; 223: 501-506

38. Pogrel M A, Thamby S. Permanent nerve involvement resulting from inferior alveolar nerve blocks. J Am Dent Assoc 2000; 131: 901-907.

39. Pogrel A. Permanent nerve damage from inferior alveolar nerve blocks an update to include articaine. J Calif Dent Assoc 2007; 35: 271-273.

40. Pogrel A. Permanent nerve damage from inferior alveolar nerve blocks: a current update. J Calif Dent Assoc 2012; 40: 795-797. 